\title{
Mental Health Needs of an Emerging Latino Community
}

\author{
Linda Bucay-Harari, MPH \\ Kathleen R. Page, MD \\ Noa Krawczyk, PhD \\ Yvonne P. Robles, MPH \\ Carlos Castillo-Salgado, MD, JD, MPH, DrPH
}

\begin{abstract}
Over the last decade, Baltimore has become a non-traditional sanctuary city, receiving an unprecedented influx of Latino immigrants, mostly from Central America's Northern Triangle, who are often fleeing violence in their home countries. This study explored the nature and frequency of healthcare utilization for mental health problems among uninsured/uninsurable Latinos who received outpatient care between 2012 and 2015 through an academic hospital-affiliated program that covers primary and specialty services to uninsured patients without regard to documentation status. Encounters for mental health disorders were the most common category, accounting for $14.88 \%$ of all visits. Mood (78\%) and anxiety disorders (16\%) were the most prevalent mental health diagnoses. The most frequent reason to seek care was symptom, signs, and ill-defined conditions (37.47\%), and within this subgroup, pain was the leading cause of seeking care (88\%), which may indicate high rates of somatization of mental health distress. This study presents a unique opportunity to explore the burden and nature of mental health needs among a population for which healthcare information is rarely attainable and highlights the need for culturally competent screening mechanisms and interventions to address the stressors faced by emergent communities.
\end{abstract}

Address correspondence to Carlos Castillo-Salgado, MD, JD, MPH, DrPH, Department of Epidemiology, Global Public Health Observatory, Johns Hopkins Bloomberg School of Public Health, 615 N. Wolfe Street. Room E6136, Baltimore, MD 21205, USA.

Linda Bucay-Harari, MPH, Department of Epidemiology, Global Public Health Observatory, Johns Hopkins Bloomberg School of Public Health, Baltimore, MD, USA.

Yvonne P. Robles, MPH, Department of Epidemiology, Global Public Health Observatory, Johns Hopkins Bloomberg School of Public Health, Baltimore, MD, USA.

Kathleen R. Page, MD, Division of Infectious Diseases, Johns Hopkins University School of Medicine, Baltimore, MD, USA.

Noa Krawczyk, PhD, Department of Mental Health, Johns Hopkins University and Johns Hopkins Bloomberg School of Public Health, Baltimore, MD, USA.

Journal of Behavioral Health Services \& Research, 2020. 388-398. (C) 2020 The Author(s). DOI 10.1007/s11414-02009688-3 


\section{Introduction}

Latinos are the largest and fastest-growing minority in the USA. In 2015, $17.6 \%$ of the population (56.6 million people) were identified as Hispanic or Latino, ${ }^{1}$ and by 2060 , this proportion is estimated to increase to $28.6 \%$. ${ }^{2}$ US-born Latinos outnumber foreign-born Latinos in most states with the exception of the District of Columbia and Maryland ${ }^{3,4}$, and around 11 million Latino immigrants in the USA are undocumented. ${ }^{5}$ Immigration trends have changed in recent years, with an unprecedented number of people coming from Honduras, El Salvador, and Guatemala, a region known as Central America's Northern Triangle (NT), shifting the social fabric of some communities that are traditionally mostly comprised of individuals of Mexican descent and forming new ones. ${ }^{6-8}$ Latino immigrants have traditionally moved to border states or regions with large well-established Latino communities and strong social support networks for newly arrived populations. In the last two decades, however, the influx of Latino immigrants has expanded to nontraditional areas, such as Baltimore City, where the Latino population increased $135 \%$ between 2000 and 2010. ${ }^{9}$ According to the Maryland Department of Health and Mental Hygiene, in 2013 around $40 \%$ of the Latino population in Maryland was from the NT. ${ }^{10}$ Immigrant communities in emergent settlement areas like Baltimore face challenges due to a lack of social support and culturally and linguistically competent services that are more accessible in traditional Latino destinations.

Migration is a process that involves several stressors. ${ }^{11}$ Undocumented immigrants are particularly vulnerable since they face unique risks and exposure to traumatic experiences before, during, and after migrating that put them at high risk of mental health distress. ${ }^{12-15}$ The NT countries have among the highest social inequality rates in the Western Hemisphere and homicide rates in the world ${ }^{6,16}$ In 2012, all three NT countries had among the top 5 highest murder rates in the world, ${ }^{6}$ and hundreds of thousands have fled the increasing violence in the area by migrating north, either to Mexico or the USA. In addition, the journey through Mexico is particularly risky for Central American migrants. ${ }^{15,}{ }^{17}$ A high proportion suffer unintentional injuries and various forms of violence, such as theft, extortion, mugging, kidnapping, trafficking, and sexual abuse perpetrated by Mexican gangs and federal officials that take advantage of their vulnerable status. ${ }^{15,17,18}$ Once in the USA, immigrants face additional stressors related to their documentation status, language and cultural barriers, fear of family separation, discrimination, and limited access to healthcare and public services. ${ }^{19,} 20$

Despite these challenges, some evidence indicates that Latin American immigrants living in the USA have better overall health than US-born Latinos and non-Latino Whites. ${ }^{21}$ A study that analyzed data from a national representative survey found that Mexican immigrants had a lower lifetime risk of developing mental disorders compared to US-born Latinos and non-Latinos. ${ }^{22}$ This phenomenon has been described as the "Hispanic paradox," ${ }^{21}$ which is often attributed to either a "healthy migrant effect," 23 in which migration itself requires a physical and mental level of fitness and is a self-selecting process or that coping skills inherent to Latino culture such as positive reframing and religion may be protective factors against stress and mental health problems. ${ }^{24}$ Some researchers, however, have argued that aggregating Latinos into one group might hinder the identification of specific vulnerabilities and protective factors among subgroups. ${ }^{11}$ It has been reported, for example, that health among Latinos varies based on country of origin, specific mental health disorder, time living in the USA, and other socioeconomic variables. ${ }^{25}$

Assessing mental health among this population is highly relevant in today's sociopolitical climate, given recent changes to border control, refugee, and immigration policies that may impact the experience of new Latino immigrants to the USA. In addition, older studies do not reflect the impact on the mental health of immigrants related to changes in immigration policy over the last two decades, starting with the Bush administration (2001-2008) deporting 2 million immigrants, continued by the Obama administration deporting 3 million immigrants (2009-2016), ${ }^{26}$ and followed by increasing anti-immigrant rhetoric and the zero-tolerance policy of the Trump Administration. ${ }^{27}$ Migrants, including families with children, facing violence and extortion 
continue to migrate to the USA in hopes of receiving asylum protection. ${ }^{28}$ However, the Department of Justice has been asked to prosecute "all adult aliens apprehended crossing the border illegally, with no exception for asylum seekers or those with minor children." ${ }^{27}$ The deleterious impact of these policies on the mental health of immigrants is beginning to be documented in the literature. ${ }^{29}$ For example, recent studies indicate that Latina mothers have reported high rates of anxiety, stress, and depressive symptoms caused by different stressors such as persecution, physical and sexual abuse, extortion, and separation from their children. ${ }^{30,31}$

There is limited information about healthcare utilization for mental health disorders among undocumented immigrants. This is largely due to formidable barriers to healthcare for this population due to restrictions in access to public health insurance, as well as limited to private and employer-based health insurance. ${ }^{32}$ Uninsured patients have also shown to face poor access to care, quality of care, and health outcomes. ${ }^{33,}{ }^{34}$ Gaining a better understanding of the mental health needs and the way in which this group reports symptoms of emotional distress will help providers and health systems to better serve the needs of immigrants, especially in communities such as Baltimore that are facing unprecedented new waves of immigration.

In 2009, Johns Hopkins Medicine established the Access Partnership (TAP) to provide specialty services to uninsured residents of the East Baltimore community surrounding Johns Hopkins Hospital and Johns Hopkins Bayview Medical Center. ${ }^{35}$ Since the expansion of Medicaid through the Affordable Care Act, and as uninsurance rates have declined in Maryland, ${ }^{36}$ undocumented Latino immigrants (who are ineligible to enroll in Medicaid) have become the primary utilizers of TAP, providing a unique opportunity to evaluate patterns of healthcare utilization among uninsured/uninsurable Latinos who qualify for the program. To be eligible for the TAP program, patients must be referred to care by a community primary care provider, be uninsured/uninsurable, and demonstrate financial need. The purpose of this study is to explore the nature and frequency of healthcare utilization for mental health and related problems among uninsured/uninsurable Latinos who received outpatient care at the Johns Hopkins Hospital and Johns Hopkins Bayview Medical Center through the TAP program in Baltimore City between 2012 and 2015.

\section{Methods}

Data for TAP-enrolled male and female patients over age 16 from outpatient visits at the Johns Hopkins Hospital and Johns Hopkins Bayview Medical Center were analyzed. An integrated database of demographic and healthcare utilization information for all outpatient encounters among patients who identified as Latino and received care through the TAP program between 2012 and 2015 was used. Descriptive statistics were used to illustrate the demographic characteristics of the patients and their medical diagnoses using the International Classification of Diseases, Ninth Edition (ICD-9 $)^{37}$ and non-personal identifiers that allowed the integration of the data. This study was approved by the Johns Hopkins School of Medicine Institutional Review Board.

All ICD-9 categories and codes were specified for each patient encounter in the dataset. First, the number and proportion of encounters were calculated by gender and by broad ICD-9 categories in order to assess the frequency of different types of health conditions for which care was being sought among the population of interest. To analyze the frequency of encounters for specific mental health diagnoses, the ICD-9 mental disorder category was further subdivided into six broad diagnostic categories based on how the codes were used in the Diagnostic and Statistical Manual of Mental Disorders, Fourth Edition (DSM-IV). ${ }^{38}$ These versions were used on the present report because the ICD-10 and DSM-V were only used widely after the data collection period. The DSM provides a more comprehensive framework to understand the most important groups of mental health disorders. This reclassification was based on the methods used by Hogue and colleagues in $2002^{39}$ and include the following eight categories: substance-related disorders, adjustment 
disorders, mood disorders, personality disorders, psychotic disorders, anxiety disorders, somatoform/dissociative disorders, and other mental disorders.

\section{Results}

Between 2012 and 2015, a total of 1735 patients received outpatient medical care through the TAP program, generating a total of 17,010 encounters (with a median of 5 visits per patient). Of all patients in the TAP database, 870 , or 50\%, identified as Hispanic/Latino, accounting for 6464 or $38 \%$ of the encounters in the database. Among encounters involving Latino patients, the average age was 44 years old (range 16 to $82)$, and females received a greater proportion of care $(57 \%)$ than males.

A total of 65 patients, or $7.47 \%$ of all Latino patients in the dataset, received a mental health diagnosis (Table 1). However, healthcare utilization (number of visits/encounters) was highest for mental health disorders compared to other diagnostic categories, accounting for 784 or $14.88 \%$ of all encounters among Latinos. Encounters for symptoms, signs, and ill-defined conditions (SSIDC) were the second highest diagnostic category (10.82\%), followed by a range of other health conditions, presented in order of frequency in Table 1.

Most mental health encounters occurred in a psychology community physician setting (84\%), followed by the intensive outpatient community psychiatry program $(11 \%)$, which is a specialty service with several levels of intensity formed by a team of therapists and psychiatrists. Females accounted for the majority of mental health encounters $(67 \%$, Table 2). The majority (78\%) of mental health encounters was for mood disorders, with 530 encounters for major depression and depressive disorders. Anxiety disorders accounted $16 \%$ of mental health encounters, followed by adjustment, psychotic, and alcohol-related conditions.

The most frequent reason to seek care among Latino patients was SSIDC (37.47\%). Previous research has linked SSIDC with physical non-specified symptomatology that can be rooted in mental health distress. ${ }^{40,41}$ A high number of isolated signs and symptoms were found, and the ones associated with mental health causes ${ }^{42-44}$ were selected and categorized according to their clinical manifestation. Within this subgroup of categories, pain was the leading cause to seek care (88\%). The most common form of reported pain was abdominal (55.91\%), followed by headache, head and neck symptoms (19\%) and chest (10\%). Females also made up the majority of patients with SSIDC (61\%).

\section{Implications for Behavioral Health}

This descriptive study found high levels of healthcare utilization for mental health disorders - particularly depressive and anxiety disorders - among uninsured/uninsurable Latino immigrants in an emerging community. It also presents a unique opportunity to explore the burden and nature of health and mental health disorders among an emerging Latino community for which healthcare information is rarely attainable. Most of the available research on Latino mental health has been conducted in regions where there are larger and well-established communities composed mainly by Mexican immigrants, with stronger social networks, and, in some cases, more available health and social services. Latino immigrants living in new settlement areas, especially those without documents and as immigration policy has toughened, face considerable stressors that might place them at risk for mental health disorders. Previous studies have shown that Latinos are less likely to seek and access mental healthcare than other racial/ethnic groups. ${ }^{14,45} \mathrm{We}$ found that only $7.47 \%$ of Latinos who accessed the TAP program were referred to mental health services, which is consistent with previous findings that suggest that immigrants (Hispanic and non-Hispanic) have lower lifetime risk of developing psychiatric disorders than natives, pointing out how the "Hispanic" or "immigrant" paradox influences mental health outcomes. Still, mental health visits accounted for the largest number of encounters and utilization of healthcare in the TAP program. This might indicate a higher mental health symptom severity among this group. Alternatively, this may also reflect a lack of effective and culturally appropriate services that may lead to continued symptomology and repeated use of services. 
Table 1

Number of encounters by ICD-9 category, among patients with Hispanic origin 2012-2015

\begin{tabular}{|c|c|c|c|c|}
\hline ICD-9 Category & $\begin{array}{l}\text { Female } \\
\text { encounters }\end{array}$ & $\begin{array}{l}\text { Males } \\
\text { encounters }\end{array}$ & $\begin{array}{l}\text { All } \\
\text { encounters } \\
N(\%)\end{array}$ & $\begin{array}{l}\text { Number of } \\
\text { unique } \\
\text { patients } N(\%)\end{array}$ \\
\hline Mental disorders & 525 & 259 & $784(14.88 \%)$ & $65(7.47 \%)$ \\
\hline $\begin{array}{l}\text { Symptoms, signs, and ill-defined } \\
\text { conditions }\end{array}$ & 339 & 231 & $570(10.82 \%)$ & $326(37.4 \%)$ \\
\hline Neoplasms & 264 & 299 & $563(10.69 \%)$ & $71(8.16 \%)$ \\
\hline $\begin{array}{l}\text { Diseases of the nervous system } \\
\text { and sense organs }\end{array}$ & 239 & 237 & $476(9.04 \%)$ & $174(20.00 \%)$ \\
\hline $\begin{array}{l}\text { Encounter for specific } \\
\text { procedures and after care }\end{array}$ & 238 & 185 & $423(8.03 \%)$ & $96(11.03 \%)$ \\
\hline $\begin{array}{l}\text { Diseases of the genitourinary } \\
\text { system }\end{array}$ & 271 & 130 & $401(7.61 \%)$ & $187(21.49 \%)$ \\
\hline $\begin{array}{l}\text { Endocrine, nutritional, metabolic } \\
\text { diseases, and immunity } \\
\text { disorders }\end{array}$ & 172 & 114 & $286(5.43 \%)$ & $103(11.84 \%)$ \\
\hline Diseases of the digestive system & 95 & 139 & $234(4.44 \%)$ & $116(13.33 \%)$ \\
\hline $\begin{array}{l}\text { Diseases of the musculoskeletal } \\
\text { system and connective tissue }\end{array}$ & 76 & 129 & $205(3.89 \%)$ & $114(13.10 \%)$ \\
\hline $\begin{array}{l}\text { Complications of pregnancy, } \\
\text { childbirth, and the puerperium }\end{array}$ & 196 & - & $196(3.72 \%)$ & $60(6.90 \%)$ \\
\hline $\begin{array}{l}\text { Diseases of the skin and } \\
\text { subcutaneous tissue }\end{array}$ & 99 & 82 & $181(3.44 \%)$ & $51(5.86 \%)$ \\
\hline $\begin{array}{l}\text { Persons w/o reported diagnosis } \\
\text { encountered during exam }\end{array}$ & 99 & 79 & $178(3.38 \%)$ & $146(16.78 \%)$ \\
\hline $\begin{array}{l}\text { Diseases of the circulatory } \\
\text { system }\end{array}$ & 66 & 97 & $163(3.09 \%)$ & $58(6.67 \%)$ \\
\hline Injury and poisoning & 34 & 86 & $120(2.28 \%)$ & $72(8.28 \%)$ \\
\hline $\begin{array}{l}\text { Encountering related to } \\
\text { reproduction and development }\end{array}$ & 97 & 1 & $98(1.86 \%)$ & $26(2.99 \%)$ \\
\hline Infectious and parasitic diseases & 25 & 42 & $67(1.27 \%)$ & $31(3.56 \%)$ \\
\hline $\begin{array}{l}\text { Diseases of the respiratory } \\
\text { system }\end{array}$ & 31 & 24 & $55(1.04 \%)$ & $34(3.91 \%)$ \\
\hline $\begin{array}{l}\text { Persons with a condition } \\
\text { influencing their health status }\end{array}$ & 26 & 28 & $54(1.03 \%)$ & $29(3.33 \%)$ \\
\hline Congenital anomalies & 20 & 32 & $52(0.99 \%)$ & $26(2.99 \%)$ \\
\hline $\begin{array}{l}\text { Encounter health services in } \\
\text { other circumstances }\end{array}$ & 29 & 18 & $47(0.89 \%)$ & $39(4.48 \%)$ \\
\hline $\begin{array}{l}\text { Persons w/hazards related to } \\
\text { communicable disease }\end{array}$ & 8 & 32 & $40(0.76 \%)$ & $23(2.64 \%)$ \\
\hline Missing category & 16 & 13 & $29(0.55 \%)$ & $25(2.87 \%)$ \\
\hline $\begin{array}{l}\text { Diseases of the blood and } \\
\text { blood-forming organs }\end{array}$ & 26 & 2 & $28(0.53 \%)$ & $11(1.26 \%)$ \\
\hline $\begin{array}{l}\text { Persons } w / \text { hazards related to } \\
\text { personal and family history }\end{array}$ & 10 & 3 & $13(0.25 \%)$ & $11(1.26 \%)$ \\
\hline
\end{tabular}


Table 1

(continued)

\begin{tabular}{lllll}
\hline ICD-9 Category & $\begin{array}{l}\text { Female } \\
\text { encounters }\end{array}$ & $\begin{array}{l}\text { Males } \\
\text { encounters }\end{array}$ & $\begin{array}{l}\text { All } \\
\text { encounters } \\
(\%)\end{array}$ & $\begin{array}{l}\text { Number of } \\
\text { unique patients } \\
N(\%)\end{array}$ \\
\hline $\begin{array}{l}\text { Other suspected conditions not } \\
\text { found }\end{array}$ & 3 & - & $3(0.06 \%)$ & $3(0.34 \%)$ \\
$\begin{array}{l}\text { Multiple gestation placenta } \\
\text { status }\end{array}$ & 1 & - & $1(0.02 \%)$ & $1(0.1 \%)$ \\
$\begin{array}{l}\text { Other specified exposures and } \\
\text { history presenting health hazard } \\
\text { Total }\end{array}$ & - & 1 & $1(0.02 \%)$ & $1(0.1 \%)$ \\
\hline
\end{tabular}

Mood and anxiety disorders emerged as the most common mental health problems among this population, which is consistent with general global population-level prevalence estimates in which mood and anxiety disorders are often the most common mental health conditions. ${ }^{46}$

The TAP patient population of uninsured/uninsurable individuals due to documentation and socioeconomic status may be particularly vulnerable to mental health disorders given their unique experiences before and after migrating to the USA. Family separation associated with migration may be particularly stressful for people arriving in emergent immigrant areas with less established social networks and services than more traditional settlement areas. In addition, exposure to violence is common in this population and has shown to cause profound damage in the physical and mental health of the victims, ${ }^{47}$ commonly expressed as anxious and depressive symptomatology. ${ }^{48,}{ }^{49}$ Moreover, populations that face the cumulative effect of poverty, malnutrition, lack of political representation, and other socioeconomic stressors might suffer an exacerbation of their prior mental health distress when they are exposed to other forms of violence such as armed conflict. ${ }^{50}$ Indeed, previous evidence shows that the new wave of migrants from the NT have significant mental health symptoms as consequence of violence and persecution. A study conducted at the US-Mexico border ${ }^{48}$ showed that the vast majority $(83 \%)$ reported violence as a reason to migrate and at least half were exposed to highly traumatic experiences in their home countries. Respondents in this study reported high rates of psychological distress (one third PTSD, one quarter major depressive disorder, and $17 \%$ reported symptoms that satisfied criteria for both conditions).

Latinos have also been shown to be more likely than non-Latinos to somatize psychological distress ${ }^{41,43}$ and tend to rely on the general medical sector rather than seeking specialty mental health services. ${ }^{51}$ This information is important to note given that SSIDC was both the most common diagnostic category to seek care among Latinos receiving TAP services and second most common health service encounter. This ICD-9 category refers to symptoms, signs, and laboratory results where no diagnosis classifiable elsewhere was recorded and could potentially be related to a certain degree with mental distress.

Members of different sociocultural groups have shown to experience stress and emotional suffering in diverse ways. ${ }^{42,}{ }^{52}$ In some cases, symptoms fit the description of a specific disorder according to the DSM, but at other times, affective distress can be expressed as an undefined and generalized form of anxiety or depression. ${ }^{43,53}$ Medically unexplained symptoms represent an important burden to the healthcare system, and it has been estimated that they account for approximately a quarter to half of all patient visits in primary care settings in the USA. ${ }^{41,43,54}$

In clinical settings, SSIDC such as that found frequently in this study may present as isolated symptoms, but it has been argued that in some cultural contexts, these symptoms might be more 


\section{Table 2}

Detailed encounters with ICD-9 codes for mental disorders according to DSM-IV categories, among patients with Hispanic origin 2012-2015

\begin{tabular}{|c|c|c|c|c|}
\hline & ICD-9 codes & Females & Males & $\begin{array}{l}\text { All } \\
\text { encounters } \\
\quad N(\%)\end{array}$ \\
\hline \multicolumn{2}{|l|}{ Mood disorders } & 402 & 206 & $608(77.55 \%)$ \\
\hline Major depression & $\begin{array}{l}296.20,296.22,296.30,296.31,296.32 \\
296.33296 .34,296.35,296.36\end{array}$ & 310 & 164 & 474 \\
\hline $\begin{array}{l}\text { Depressive } \\
\text { disorder (NEC) }\end{array}$ & 311 & 44 & 12 & 56 \\
\hline Bipolar disorder & $296.40,296.45,296.5,296.6,296.7$ & 37 & 5 & 42 \\
\hline $\begin{array}{l}\text { Other episodic } \\
\text { mood disorder }\end{array}$ & $296.80,296.89,296.90$ & 11 & 25 & 36 \\
\hline \multicolumn{2}{|l|}{ Anxiety disorders } & 84 & 44 & $128(16.33 \%)$ \\
\hline $\begin{array}{l}\text { Anxiety, } \\
\text { unspecified }\end{array}$ & 300.00 & 24 & 16 & 40 \\
\hline Panic disorders & $300.01,300.21$ & 34 & 1 & 35 \\
\hline $\begin{array}{l}\text { Post-traumatic } \\
\text { stress disorder }\end{array}$ & 309.81 & 23 & 10 & 33 \\
\hline $\begin{array}{l}\text { General anxiety } \\
\text { disorder }\end{array}$ & 300.02 & 3 & 17 & 20 \\
\hline \multicolumn{2}{|l|}{ Adjustment disorders } & 26 & 1 & $27(3.44 \%)$ \\
\hline $\begin{array}{l}\text { Adjustment, } \\
\text { unspecified }\end{array}$ & 309.9 & 9 & 1 & 10 \\
\hline $\begin{array}{l}\text { Adjustment w/ } \\
\text { disturbance }\end{array}$ & $309.24,309.28$ & 4 & 0 & 4 \\
\hline $\begin{array}{l}\text { Adjustment w/ } \\
\text { depressed mood }\end{array}$ & 309.0 & 13 & 0 & 13 \\
\hline \multicolumn{2}{|c|}{ Psychotic disorders and symptoms } & 7 & 1 & $8(1.02 \%)$ \\
\hline $\begin{array}{l}\text { Depressive-type } \\
\text { psychosis }\end{array}$ & 298.0 & 6 & 0 & 6 \\
\hline $\begin{array}{l}\text { Unspecified } \\
\text { psychosis }\end{array}$ & 298.9 & 1 & 0 & 1 \\
\hline $\begin{array}{l}\text { Paranoid-type } \\
\text { schizophrenia }\end{array}$ & 295.30 & 0 & 1 & 1 \\
\hline \multicolumn{2}{|c|}{ Alcohol-related disorders and symptoms } & 0 & 5 & $5(0.64 \%)$ \\
\hline $\begin{array}{l}\text { Alcohol } \\
\text { withdrawal }\end{array}$ & 291.81 & 0 & 1 & 1 \\
\hline $\begin{array}{l}\text { Non-dependent } \\
\text { alcohol abuse }\end{array}$ & 305.00 & 0 & 4 & 4 \\
\hline \multicolumn{2}{|c|}{ Other mental disorders and symptoms } & 6 & 2 & $8(1.02 \%)$ \\
\hline Conduct disorder & 312.00 & 0 & 1 & 1 \\
\hline $\begin{array}{l}\text { Psychosexual } \\
\text { disorders }\end{array}$ & $302.70,302.75$ & 1 & 1 & 2 \\
\hline Tension headache & 307.81 & 1 & 0 & 1 \\
\hline $\begin{array}{l}\text { Persistent } \\
\text { insomnia }\end{array}$ & 307.42 & 1 & 0 & 1 \\
\hline
\end{tabular}


Table 2

(continued)

\begin{tabular}{|c|c|c|c|c|}
\hline & ICD-9 codes & Females & Males & $\begin{array}{l}\text { All } \\
\text { encounters } N \\
(\%)\end{array}$ \\
\hline Bulimia nervosa & 307.51 & 1 & 0 & 1 \\
\hline $\begin{array}{l}\text { Unspecified } \\
\text { non-psychotic }\end{array}$ & 300.9 & 2 & 0 & 2 \\
\hline
\end{tabular}

sensitive indicators of traumatization than those warranting a psychiatric diagnosis (e.g., PTSD). ${ }^{42}$ Since the 1980s, the concepts of "idioms of distress," "cultural syndromes," and "culture bound syndromes" have opened research lines focused on understanding the different ways in which diverse sociocultural groups communicate individual and collective suffering via reference to shared beliefs and local ideas about the functioning of the body and mind. ${ }^{42,52,53,55}$ For example, previous literature has described an idiom of distress common among Latinos, padecer de los nervios, which is usually characterized by chronic anxiety, pain, depression, somatization, and/or dissociation, as well as acute symptoms such as palpitations, shortness of breath, or trembling. ${ }^{44,56}$

Further research is needed to understand the different markers or expressions of how members of emerging communities face adversity and vulnerability, which can inform the development of better screening mechanisms and tools to identify mental health problems in a culturally appropriate way, improving the detection of those in need of services. ${ }^{52}$ As the US population grows more diverse, it is important to develop culturally and linguistically competent services and a diverse healthcare workforce that are familiar with the culturally specific manifestations of mental health distress among different groups, so they can frame the treatment options in an appropriate and non-threatening way. ${ }^{57}$ Also, as suggested by Kaiser and colleagues, ${ }^{52}$ incorporating this knowledge into effective public health communication to target specific populations can decrease stigmatization around psychopathology and promote treatment-seeking behavior. More accurate detection can also increase effective care delivery. ${ }^{42,} 58$

In our study, Latino women were more likely than men to use health services in general and mental healthcare in particular. This is consistent with previous studies that show that men are less likely to seek treatment than women, even when they are experiencing the same levels of distress, a tendency that is even more pronounced among men from racial and ethnic minority backgrounds. ${ }^{59}$ One reason men may underutilize mental health services is that they have less favorable attitudes toward mental health services, rooted in traditional masculine norms and stigma surrounding mental health problems. ${ }^{60}$ Additionally, women may have had a higher utilization of healthcare compared to men because pregnancy is an important point of entry to healthcare services, and many women in Baltimore's Latino community are of reproductive age. ${ }^{4}$

The present findings should be interpreted in light of several limitations. The TAP database had limited information about the demographic characteristics of the patients, such as country of origin, documentation status, and time living in the USA. However, the eligibility criteria for TAP (uninsured/uninsurable) selects for people without documentation status since the expansion of Medicaid through the Affordable Care Act. Nonetheless, the generalizability of this data is limited to those who have access to TAP, which excludes the most vulnerable and disenfranchised migrants who do not have a primary care provider to refer them to TAP. These migrants may not have the social capital to seek care, and the inability to reach these individuals suggests that our findings may underestimate the burden of disease. The database also lacks information on severity of 
disorder and type of treatment received, as well as data about the nature, intensity, duration, and effects of treatment. Despite these limitations, this paper presents valuable information on the mental health needs of a unique and growing Latino community in the mid-Atlantic. The presented clinical manifestations in the particular case of an emerging community with a high proportion of immigrants from the NT suggest that these new communities have important mental health needs that need to be further studied. Studying factors, such as country of birth, time living in the USA, and acculturation, might be important in learning more about the extent to which the "Hispanic paradox" plays a role in mental health outcomes among emerging Latino communities comprised of non-Mexican immigrants. Given the increasing number of immigrants arriving from the NT in Baltimore and other cities in the USA, ${ }^{61}$ the medical and public health community must be aware and receptive to the type of unmet mental health needs of this marginalized population.

Finally, it is important to acknowledge that, as emphasized by multiple authors, Latinos are not a monolithic group. ${ }^{11}$ The history of each Latin American country entails complex historical, cultural, and social dynamics. Therefore, the study of contextual factors among different Latino groups, such as prior immigration experiences, exposure to violence during migration, as well as the development of social support networks and access to services during resettlement, will allow us to design comprehensive public health programs to address mental health needs of communities across the USA.

\section{Acknowledgments}

We thank Dr. Barbara Cook, medical director of The Access Partnership program, for her support during the course of this research. Noa Krawczyk received support from the National Institute of Drug Abuse Training Grant T32-DA007293 (PI: Renee Johnson).

Funding Information The authors received no specific funding for this work.

\section{Compliance with Ethical Standards}

Conflict of Interest The authors have no conflict of interest to declare.

Open Access This article is licensed under a Creative Commons Attribution 4.0 International License, which permits use, sharing, adaptation, distribution and reproduction in any medium or format, as long as you give appropriate credit to the original author(s) and the source, provide a link to the Creative Commons licence, and indicate if changes were made. The images or other third party material in this article are included in the article's Creative Commons licence, unless indicated otherwise in a credit line to the material. If material is not included in the article's Creative Commons licence and your intended use is not permitted by statutory regulation or exceeds the permitted use, you will need to obtain permission directly from the copyright holder. To view a copy of this licence, visit http://creativecommons.org/licenses/by/4.0/.

\section{References}

1. United States Census Bureau. UNITED STATES QuickFacts from the US Census Bureau. U.S. Department of Commerce. https:// www.census.gov/quickfacts/table/PST045215/00. Published 2015. Accessed March 6, 2017.

2. U.S. Census Bureau. FFF: Hispanic Heritage Month 2016. https://www.census.gov/newsroom/facts-for-features/2016/cb16-ff16.html. Published 2016. Accessed March 30, 2017.

3. Pew Research Center. Hispanic Population Growth and Dispersion Across U.S. Counties, 1980-2014. http://www.pewhispanic.org/ interactives/hispanic-population-by-county/. Published 2014. Accessed March 6, 2017. 
4. Maryland Department of Health and Mental Hygiene. Hispanics in Maryland: Health Data and Resources. https:// health.maryland.gov/mhhd/Documents/Maryland-Hispanic-Health-Disparity-Data.pdf. Published 2013. Accessed June 4, 2017.

5. Pew Research Center Hispanic Trends. Unauthorized Immigrants in the U.S., 2012. Pew Research Center Hispanic Trends. http:// www.pewhispanic.org/interactives/unauthorized-immigrants-2012/. Published 2014.

6. Stinchcomb D, Hershberg E. Unaccompanied Migrant Children from Central America: Context, Causes, and Responses.; 2014. doi:https://doi.org/10.2139/ssrn.2524001.

7. Robles F. Fleeing Gangs, Children Head to U.S. Border - The New York Times. The New York Times. https://www.nytimes.com/ 2014/07/10/world/americas/fleeing-gangs-children-head-to-us-border.html?_r=0. Published 2014. Accessed March 7, 2017.

8. Pew Research Center. Birth regions and nations of Unauthorized Immigrants in the US. http://www.pewhispanic.org/2016/09/20/1birth-regions-and-nations/. Published 2016. Accessed February 8, 2016.

9. US Census Bureau. American factfinder. doi:https://doi.org/10.5860/CHOICE.43-1925.

10. Maryland Department of Health and Mental Hygiene. Hispanics in Maryland: Health Data and Resources. http://dhmh.maryland.gov/ mhhd/Documents/Maryland-Hispanic-Health-Disparity-Data.pdf. Published 2013. Accessed April 30, 2017.

11. Alarcon RD, Parekh A, Wainberg ML, Duarte CS, Araya R, Oquendo MA. Hispanic immigrants in the USA: social and mental health perspectives. The Lancet Psychiatry. 2016;3(9):860-870. doi:https://doi.org/10.1016/S2215-0366(16)30101-8.

12. Cabassa LJ, Lester R, Zayas LH. "It's like being in a labyrinth": Hispanic immigrants" perceptions of depression and attitudes toward treatments. Journal of Immigrant and Minority Health. 2007;9(1):1-16. doi:https://doi.org/10.1007/s10903-006-9010-1.

13. Chu T, Keller AS, Rasmussen A. Effects of post-migration factors on PTSD outcomes among immigrant survivors of political violence. Journal of Immigrant and Minority Health. 2013;15(5):890-897. doi:https://doi.org/10.1007/s10903-012-9696-1.

14. Breslau J, Borges G, Tancredi D, et al. Migration from Mexico to the United States and subsequent risk for depressive and anxiety disorders: a crossnational study. Archives of General Psychiatry. 2011;68(4):428-433. doi:https://doi.org/10.1001/archgenpsychiatry.2011.21.

15. Amnesty International. Invisible Victims - Migrants on the Move in Mexico.; 2010. https://www.amnesty.org/en/documents/AMR41/ 014/2010/en/. Accessed March 7, 2017.

16. Economic Commission for Latin America and the Caribbean. Statistical Yearbook for Latin America and the Caribbean. 2013.

17. Infante C, Idrovo AJ, Sánchez-Domínguez MS, et al. Violence committed against migrants in transit: Experiences on the Northern Mexican border. Journal of Immigrant and Minority Health. 2012;14(3):449-459. doi:https://doi.org/10.1007/s10903-011-9489-y.

18. Alessi EJ, Kahn S, Chatterji S. "The darkest times of my life": Recollections of child abuse among forced migrants persecuted because of their sexual orientation and gender identity. Child Abuse \& Neglect. 2016;51:93-105. doi:https://doi.org/10.1016/ j.chiabu.2015.10.030.

19. Simich LF. Hidden Meanings of Health Security: Migration Experiences and Systemic Barriers to Mental Wellbeing among Non-status Migrants. International Journal of Migration, Health and Social Care. 2006;2(3/4):16-27. doi:https://doi.org/10.1108/ 17479894200600024

20. Dwyer J. Illegal immigrants, health care, and social responsibility. The Hastings Center Report. 2004;34(1):34-41. doi:https://doi.org/ $10.2307 / 3528249$.

21. Markides KS, Coreil J. The health of Hispanics in the southwestern United States: an epidemiologic paradox. Public Health Reports. 1986;101(3):253-265.

22. Breslau J, Aguilar-Gaxiola S, Borges G. Risk for Psychiatric Disorder among Immigrants and Their US-Born Descendants: Evidence from the National Comorbidity Survey-Replication. The Journal of Nervous and Mental Disease. 2007;195(3):189.

23. McDonald JT, Kennedy S. Insights into the "healthy immigrant effect": Health status and health service use of immigrants to Canada. Social Science \& Medicine. 2004;59(8):1613-1627. doi:https://doi.org/10.1016/j.socscimed.2004.02.004.

24. Farley T, Galves A, Dickinson LM, et al. Stress, coping, and health: A comparison of Mexican immigrants, Mexican-Americans, and non-Hispanic Whites. Journal of Immigrant Health. 2005;7(3):213-220. doi:https://doi.org/10.1007/s10903-005-3678-5.

25. Alegría M, Mulvaney-Day N, Torres M, et al. Prevalence of Psychiatric Disorders Across Latino Subgroups in the United States. American Journal of Public Health. 2007;9797(1):68-75. doi:https://oi.org/10.2105/AJPH.2006.087205.

26. Radford J. Key findings about U.S. immigrants. Pew Research Center. Pew Research Center. doi:https://doi.org/10.1146/ annurev.matsci.38.060407.132434

27. CRS CRS. The Trump Administration's "Zero Tolerance" Immigration Enforcement Policy;; 2019. https://crsreports.congress.gov. Accessed August 23, 2019.

28. United Nations High Commissioner for Refugees. Northern Triangle of Central America Situation Factsheet (February 2017). UN High Commissioner for Refugees. https://www.refworld.org/country,,UNHCR,,MEX,,58aae2bb4,0.html. Published 2017. Accessed August 23, 2019

29. Miller A, Hess JM, Bybee D, et al. Understanding the mental health consequences of family separation for refugees: Implications for policy and practice. American Journal of Orthopsychiatry. 2018;88(1):26-37. doi:https://doi.org/10.1037/ort0000272.

30. McCabe BE, Mitchell EM, Gonzalez-Guarda RM, et al. Transnational Motherhood: Health of Hispanic Mothers in the United States Who Are Separated From Children. Journal of Transcultural Nursing. 2017;28(3):243-250. doi:https://doi.org/10.1177/ 1043659616644960

31. Stange M, Stark B. The Ethical and Public Health Implications of Family Separation. Journal of Law, Medicine \& Ethics. 2019;47(2_suppl):91-94. doi:https://doi.org/10.1177/1073110519857327.

32. Artiga S, Diaz M. Health Coverage and Care of Undocumented Immigrants.; 2019. https://www.pewhispanic.org/interactives/ unauthorized-trends/. Accessed September 3, 2019.

33. Rodríguez MA, Vargas Bustamante A, Ang A. Perceived quality of care, receipt of preventive care, and usual source of health care among undocumented and other Latinos. Journal of General Internal Medicine. 2009;24(3 SUPPL.):508-521. doi:https://doi.org/ 10.1007/s11606-009-1098-2.

34. Committee on the Consequences of Uninsurance. Care without Coverage: Too Little, Too Late. Vol 97.; 2005. www.nap.edu. Accessed September 3, 2019. 
35. Handy C, Ma S, Block L, et al. Identifying Patient, Community and Program Specific Barriers to Free Specialty Care Utilization by Uninsured Patients in East Baltimore. Journal of Health Care for the Poor and Underserved. 2013;24(2):688-696. doi:https://doi.org/ 10.1353/hpu.2013.0085.

36. Berchick ER, Hood E, Barnett JC. Health Insurance Coverage in the United States: 2017 Current Population Reports.; 2018. https:// www.census.gov/content/dam/Census/library/publications/2018/demo/p60-264.pdf. Accessed September 3, 2019.

37. World Health Organization. International Classification of Diseases, 10th revision (ICD-10). World Health Organization. 2013.

38. American Psychiatric Association. Diagnostic and statistical manual of mental disorders: DSM-IV-TR. Washington, DC: American Psychiatric Association. 2000.

39. Hoge CW, Lesikar SE, Guevara R, et al. Mental disorders among U.S. military personnel in the 1990s: Association with high levels of health care utilization and early military attrition. American Journal of Psychiatry. 2002;159(9):1576-1583. doi:https://doi.org/10.1176/ appi.ajp.159.9.1576.

40. Roy MJ, Koslowe PA, Kroenke K, et al. Signs, symptoms, and ill-defined conditions in Persian Gulf War veterans: findings from the Comprehensive Clinical Evaluation Program. Psychosomatic Medicine. 1998;60(6):663-668. http://www.ncbi.nlm.nih.gov/pubmed/ 9847023\%5Cnhttp://www.psychosomaticmedicine.org/content/60/6/663.full.pdf. Accessed April 30, 2017.

41. Barsky AJ, Orav EJ, Bates DW. Somatization increases medical utilization and costs independent of psychiatric and medical comorbidity. Archives of General Psychiatry. 2005;62(8):903-910. doi:https://doi.org/10.1001/archpsyc.62.8.903.

42. Hinton DE, Lewis-Fernández R. Idioms of distress among trauma survivors: Subtypes and clinical utility. Culture, Medicine, and Psychiatry. 2010;34(2):209-218. doi:https://doi.org/10.1007/s11013-010-9175-x.

43. Angel R, Guarnaccia PJ. Mind, body, and culture: Somatization among Hispanics. Social Science \& Medicine. 1989;28(12):12291238. doi:https://doi.org/10.1016/0277-9536(89)90341-9

44. Guarnaccia PJ, Farias P. The social meanings of nervios: A case study of a central American woman. Social Science \& Medicine. 1988;26(12):1223-1231. doi:https://doi.org/10.1016/0277-9536(88)90154-2.

45. Alegría M, Chatterji P, Wells K, et al. Disparity in Depression Treatment Among Racial and Ethnic Minority Populations in the United States. Psychiatric Services. 2008;59(11):1264-1272. doi:https://doi.org/10.1176/appi.ps.59.11.1264.

46. Kessler RC, Angermeyer M, Anthony JC, et al. Lifetime prevalence and age-of-onset distributions of mental disorders in the World Health Organization's World Mental Health Survey Initiative. World Psychiatry. 2007;6(3):168-176. doi:https:/doi.org/10.1001/ archpsyc.62.6.593.

47. Fortuna LR, Porche M V, Alegria M. Political violence, psychosocial trauma, and the context of mental health services use among immigrant Latinos in the United States. Ethn Health. 2008;13(5):435-463. doi:https://doi.org/10.1080/13557850701837286.

48. Keller A, Joscelyne A, Granski M,et al. Pre-Migration Trauma Exposure and Mental Health Functioning among Central American Migrants Arriving at the US Border. PLoS One. 2017:1-11. doi:https://doi.org/10.1371/journal.pone.0168692.

49. Molesky J. Pathology of Central American refugees. Migration World Magazine. 1986;14(4):19-23. http://www.scopus.com/inward/ record.url?eid=2-s2.0-0022932471\&partnerID=40\&md5=7dcc24645702a530b22414453b0ea1cb.

50. Miller KE, Rasmussen A. War exposure, daily stressors, and mental health in conflict and post-conflict settings: Bridging the divide between trauma-focused and psychosocial frameworks. Social Science \& Medicine. 2010;70(1):7-16. doi:https://doi.org/10.1016/ j.socscimed.2009.09.029.

51. Cabassa LJ, Zayas LH, Hansen MC. Latino adults' access to mental health care: A review of epidemiological studies. Administration and Policy in Mental Health and Mental Health Services Research. 2006;33(3):316-330. doi:https://doi.org/10.1007/s10488-006-0040-8.

52. Kaiser BN, Haroz EE, Kohrt BA, et al. "Thinking too much": A systematic review of a common idiom of distress. Social Science \& Medicine. 2015;147:170-183. doi:https://doi.org/10.1016/j.socscimed.2015.10.044.

53. Nichter M. Idioms of distress: alternatives in the expression of psychological distress: a case study from South India. Culture, Medicine and Psychiatry. 1981;5(Dec):379-408.

54. Barsky A, Borus J. Somatization and medicalization in the era of managed care. JAMA. 1995;274(24):1931-1934. doi:https://doi.org/ 10.1001/jama.1995.03530240041038

55. Simons R, Reidel CH-D, 1985 U. The culture-bound syndromes. Springer.

56. Lewis-Fernández R, Gorritz M, Raggio GA, et al. Association of Trauma-Related Disorders and Dissociation with Four Idioms of Distress Among Latino Psychiatric Outpatients. Culture, Medicine and Psychiatry. 2010;34:219-243. doi:https:/doi.org/10.1007/ s11013-010-9177-8.

57. Primm AB, Vasquez MJT, Mays RA, et al. The Role of Public Health in Addressing Racial and Ethnic Disparities in Mental Health and Mental Illness. Vol 7.; 2010. http://www.cdc.gov/pcd/. Accessed August 23, 2019.

58. Fabian K, Fannoh J, Washington GG, et al. "My Heart Die in Me": Idioms of Distress and the Development of a Screening Tool for Mental Suffering in Southeast Liberia. Culture, Medicine and Psychiatry. 2018;42(3):684-703. doi:https://doi.org/10.1007/s11013-018-9581-z.

59. Kessler RC, Brown RL, Broman CL. Sex Differences in Psychiatric Help-Seeking: Evidence from Four Large-Scale Surveys. Journal of Health and Social Behavior: 1981;22(1):49. doi:https://doi.org/10.2307/2136367.

60. Vogel DL, Heimerdinger-Edwards SR, Hammer JH, et al. "Boys don't cry": Examination of the links between endorsement of masculine norms, self-stigma, and help-seeking attitudes for men from diverse backgrounds. Journal of Counseling Psychology. 2011;58(3):368-382. doi:https://doi.org/10.1037/a0023688.

61. Cohn BYDV, Passel JS, Gonzalez-Barrera A. Rise in U.S. Immigrants From El Salvador, Guatemala and Honduras Outpaces Growth From Elsewhere.; 2017. https://www.pewresearch.org/hispanic/wp-content/uploads/sites/5/2017/12/Pew-ResearchCenter_Central_American-migration-to-U.S._12.7.17.pdf.

Publisher's Note Springer Nature remains neutral with regard to jurisdictional claims in published maps and institutional affiliations. 